
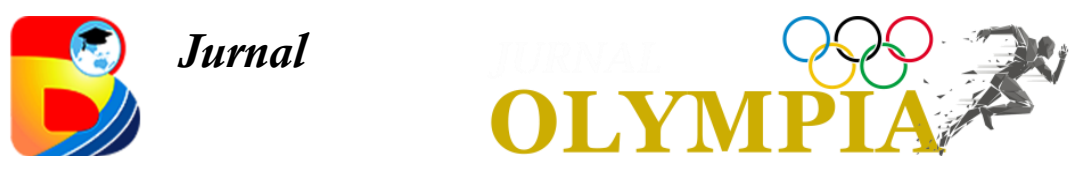

http://journal.binadarma.ac.id/index.php/olympia

\title{
Hubungan Kekuatan Otot Lengan, Koordinasi Mata Tangan dan Fleksibilitas Pergelangan Tangan Terhadap Ketepatan Long Servis Bulutangkis
}

\author{
Ince Abdul Muhaemin Mangngassai ${ }^{1}$, Andi Syaiful ${ }^{2,}$ Marsuki $^{3}$
}

Universitas Cenderawasih, Jayapura, Papua, Indonesia

\section{Info Artikel}

Sejarah Artikel:

Diterima Agustus 2020

Disetujui November 2020

Dipublikasikan Desember 2020

Keywords: Kekuatan Otot Lengan, Kordinasi Mata Tangan, Fleksibilitas Pergelangan Tangan, Ketepatan Long Servis

\section{Abstrak}

Penelitian ini bertujuan untuk mengetahui seberapa besarnya hubungan antara kekuatan otot lengan, koordinasi mata tangan dan fleksibilitas pergelangan tangan terhadap ketepatan long servis bulutangkis. Metode yang digunakan adalah korelasional. Hasil penelitian menunjukkan: (1) Terdapat korelasi yang signifikan antara kekuatan otot lengan terhadap ketepatan long servis bulutangkis $\mathrm{rx} 1 \mathrm{y}=0.779$ dengan kontribusi sebesar $60.68 \%$, (2) Terdapat korelasi yang sangat signifikan antara koordinasi mata-tangan terhadap ketepatan long servis bulutangkis dengan rx2y = 0.723 dengan kontribusi sebesar $52.57 \%$ (3) Terdapat korelasi yang signifikan antara fleksibilitas pergelangan tangan terhadap ketepatan long servis bulutangkis $\mathrm{rx} 3 \mathrm{y}=0.822$ dengan kontribusi sebesar $67.57 \%$, dan (4) Terdapat korelasi yang signifikan antara kekuatan otot lengan, koordinasi mata tangan dan fleksibilitas pergelangan tangan terhadap ketepatan long servis bulutangkis dengan $\mathrm{rx} 123 \mathrm{y}=0.942$ dengan kontribusi sebesar $88.73 \%$.

\begin{abstract}
This study aims to determine how much the relationship between arm muscle strength, hand eye coordination and wrist flexibility to the accuracy of long badminton service. The method used is correlational. The results showed: (1) There was a significant correlation between arm muscle strength and accuracy of long bad rxly service $=0.779$ with a contribution of $60.68 \%$, (2) There was a very significant correlation between eye-hand coordination to the accuracy of long bad service with $r x 2 y=0723$ with a contribution of $52.57 \%$ (3) There is a significant correlation between wrist flexibility and accuracy of badminton long service rx3y $=0.822$ with a contribution of $67.57 \%$, and (4) There is a significant correlation between arm muscle strength, hand eye coordination and flexibility wrist against the accuracy of long badminton services with rxl23y $=0.942$ with a contribution of $88.73 \%$.
\end{abstract}




\section{PENDAHULUAN}

Olahraga perlu dilakukan dalam kehidupan sehari-hari untuk menjaga kesehatan tubuh agar tetap sehat dan bugar tetapi kitapun harus mengatur jadwal secara teratur agar mendapatkan hasil yang maksiamal. Seiring perkembanganya zaman dan kemajuan ilmu pengetahuan tentang olahraga menjadi suatu aktivitas untuk ajang silaturahmi, memperbanyak teman, rekresasi dan hiburan juga di lakukan dengan tujuan untuk meningkatkan prestasi. Aktivitas olahraga dapat menyatuhkan semua komponen bangsa tanpa memandang suku, rasa maupaun agama dan tidak ada satupun orang di dunia tidak menyukai yang namanya olahraga dari kalangan bangsawan, pemimpin negara, pejabat hingga rakyat biasapun melakuakan aktivitas tersebut.

Undang-undang Republik Indonesia No 3 Tahun 2005 tentang sistem keolahragaan pasal 21 ayat 3 menjelaskan bahwa: "Pembinaan dan pengembangan keolahragaan dilaksanakan melalui tahap pengenalan olahraga, pemantauan, pemanduan serta pengembangan bakat dan peningkatan prestasi”. Manfaat olahraga bagi tubuh manusia dapat membantu melindungi dari berbagai penyakit seperti stroke, jantung, diabetes, tekanan darah tinggi, obesitas, osteoporosis, nyeri punggung, mengurangi stress dan dapat meningkatkan suasana hati, salah satunya dalam melakukan permainan olahraga bulutangkis.

Permainan bulutangkis merupakan permainan yang dapat di mainkan oleh dua orang ataupun dua pasang yang saling berlawanan. Permainan ini menggunakan raket sebagai alat pemukul dan shuttlecock sebagai objek pukul, lapangan permainan berbentuk segi panjang dan dibatasi oleh net untuk memisahkan antara daerah permainan sendiri, dan daerah permainan lawan. Permainan bulutangkis sudah sangat terkenal dan memasyarakat di lingkungan sekolah, perkampungan, perusahaan, instansi, pemerintah, perusahaan, dan lain sebagainya. Sehingga banyak club-club terbentuk baik kelompok umur junior maupun senior dan club di lingkungan perkantoran/instansi.

Dalam permaianan bulutangkis tehniktehnik dasar harus di utamakan pukulan $L o b$, Smash, Dropshop, Drive, Servis. Untuk memulai suatu permainan harus menguasai tehnik pukulan servis baik servis pendek maupun servis panjang/long. Dalam bulutangkis ada beberapa latihan teknik yang harus dikuasaidiantaranya: teknik memegang raket, teknik memukul shutle kok, teknik penguasaan kerja kaki. Latihan teknik ini diberikan setelah pemberian latihan fisik. Pada teknik memukul dibedakan menjadi pukulan overhead dapat berupa smash, lob, drop shot, netting, pukulan side arm dapat berupa drive drop, driveclear, pukulan under arm dapat berupa under hand drop dan under hand lob (Aksan, 2013:28).

Kekuatan otot lengan dibutuhkan sebagai tenaga pendorong pada saat melakukan pukulan servis. Semakin besar kekuatan otot lengan yang dihasilkan maka 
semakin keras pula pukulan yang dihasilkan. Terlebih pada pukulan servis yang menuntut laju shuttlecock yang cepat dan jatuhnya di area servis, sehingga membutuhkan kekuatan otot lengan yang besar. Semakin besar kekuatan otot lengan, maka semakin keras pula pukulan servis yang dihasilkan. Selain kekuatan otot lengan adapun pendukung dalam melakukan long servis agar tepat pada sasaran dan lawan tidak mudah mengembalikan shuttlecock, yang pendukung lain itu koordinasi mata tangan dan fleksibilitas pergelangan tangan.

Permainan bulutangkis salah satu mata kuliah yang di program bagi mahasiswa Prodi Penjas FKIP UNCEN yang wajib lulus, dari hasil pengamatan ada beberapa mahasiswa kurang mampu mengarahkan shuttlecock ke belakang dan melambung tinggi yang jatuhnya di line belakang. Oleh karena itu, sebagai salah satu upaya untuk meningkatakan ketepatan long servis dalam permainan bulutangkis adalah dengan latihan kekuatan otot lengan, kordinasi mata tangan dan fleksibilitas pergelangan tangan dimana dengan melakukan latuhan tersebut mahasiswa mampu melaksanakan long servis secara sempurna.

Berdasarakan uraian tersebut di atas maka penulis tertarik untuk mengadakan penelitian tentang "hubungan kekuatan otot lengan, kordinasi mata tangan dan fleksibilitas pergelangan tangan terhadap ketepatan long servis pada bulutangkis mahasiswa Prodi Penjas FKIP UNCEN".

\section{Long Servis}

Servis merupakan modal awal untuk bisa memenangi pertandingan. Dengan kata lain seorang pemain tidak dapat meraih angka jika tidak dapat melakukan servis forehand tinggi digunakan dalam permainan tunggal. Shuttlecock harus dipukul dengan menggunakan tenaga penuh agar Shuttlecock melayang tinggi dan jatuh tegak lurus bagian belakang garis lapangan lawan (menurut Aksan 2013:16)

Tujuan servis tinggi yang baik, antara lain: "pertama" Untuk menghindari permainan depan bagi lawan yang bagus bermain netting, "kedua" untuk mempercepat kelelahan fisik lawan, pada saat lawan sudah mulai kehabisan tenaga (daya tahan cardiorepiratori lemah), "ketiga" Mengukur kemampuan smash lawan, "keempat" Membuka posisi depan lawan (Kunta, 2010). Tahapan long servis (forehand) begitu banyak dan kompleks, sehingga memerlukan kecermatan di dalam mempelajarinya, di dalam mata kuliah bulutangkis mahasiswa dituntut untuk dapat melakuan gerakan fase persiapan, pelaksanaan dan follow through dengan baik dan benar.

Langkah-langkah pada saat melakukan long servis bersumber Tohar $d k k$ (dalam Agung Sadewa, 2016:15) yaitu 1) pegangan raket, 2) sikap berdiri, 3) gerakan ayunan raket, 4) saat impack, 5) gerakan lanjutan atau gerakan akhir.

Ketepatan dalam melakukan long servis sangat penting sekali karena dengan semakin tepatnya long servis terhadap sasaran maka 
ketepatan long servis mahasiswa semakin bagus dan semakin akurat untuk penempatan shuttlecock atau jatuhnya shuttlecock. Sebagaimana dikemukakan oleh Suharno (dalam Agryant, 2017:24) bahwa "ketepatan adalah kemampuan seseorang untuk mengarahkan suatu gerak ke suatu sasaran sesuai dengan tujuannya. Dengan kata lain bahwa ketepatan adalah kesesuaian antara kehendak (yang diinginkan) dan kenyataan (hasil) yang diperoleh terhadap sasaran (tujuan) tertentu. dan menurut M. Sajoto (dalam Antoni, 2017:55) "ketepatan adalah kemampuan seseorang dalam mengendalikan gerakangerakan bebas terhadap suatu sasaran”. Berdasarkan uraian diatas dapat disimpulkan bahwa dalam teknik dasar long servis dalam permaian bulutangkis memerlukan sasaran atau target sehingga menghasilkan long servis dengan baik dan maksimal.

\section{Hakikat Kekuatan Otot Lengan}

Kekuatan adalah tenaga kontraksi otot yang dicapai dalam sekali usaha maksimal. Usaha maksimal ini dilakukan oleh otot atau sekelompok otot untuk mengatasi suatu masalah (Ismaryati, 2011:111). Miyologie adalah ilmu yang mempelajari tentang otototot manusia terutama pada otot rangka sebagai alat penggerak tulang atau osteo (Sukirno, 2012:139). Tulang merupakan tuasnya otot, otot yang melekatkan pada tulang lalu menggerakan tulang sesuai dengan gerakan otot yang terdapat pada tulang tersebut. Sehingga orang dapat melakukan aktivitas sehari-hari sesuai dengan profesinya masing-masing.

Otot manusia terdiri dari jaringan otot, sifatnya dapat melakukan gerakan baik memendek maupun memanjang (kontraksi dan relaxi). Otot-otot anggota badan atas, yaitu otot-otot yang memperkuat persendian anggota badan atas, Seperti pada musculus bicep brachi, Tricep brachi. Otot ini berfungsi menggerakan otot lengan. Otot-otot lengan atas yang sangat dominan seperti musculus biceps barachi otot yang berkepala dua dan musculus triceps bachi, otot yang berkepala tiga. Kedua otot tersebut berorigo pada scapula. Berdasarkan uraian di atas peneliti mengambil kesimpulan bahwa kekuatan otot lengan ialah yang mana kontraksi otot dalam usaha untuk mencapai tenaga yang maksimal atau hampir maksimal dalam mengeluarkan tenaga atau menahan beban tersebut.

\section{Hakikat Kordinasi Mata Tangan}

Kordinasi adalah merupakan keharmonisan gerak sekelompok otot selama penampilan gerak tersebut menghasilkan sebuah keterampilan. Kordinasi merupakan bagian yang tak terpisahkan dari kemampuan motorik. Jadi yang dimaksud dengan koordinasi merupaka paduan dari kemampuan motorik dan keterampilan. Magill mengatakan bahwa kordinasi adalah proses gerakan mengatur otot dalam tubuh dengan suatu cara sehingga dapat menyelesaikan tujuan dengan cara yang efektif dan efisien. Lebih lanjut Bompa mengatakan bahwa kordinasi adalah kemampuan gerak dasar yang kompleks 
pendekatan berhubungan dengan kecepatan, kekuatan, daya tahan, dan kelentukan, ini merupakan faktor penting dalam menentukan dan mendapatkan teknik dan taktis sempurna. Kordinasi akan semakin baik dan gerakan menjadi makin efisien jika dilatih koordinasi, karena kinesthetic sense terdiri dari 4 faktor yang harus dikuasai yaitu: (1) posisi tubuh atau anggota-anggota tubuh, (2) gerakan yang tepat, (3) keseimbangan, dan (4) orientasi ruang (Kusnaedi, dkk 2016)

Di dalam permainan bulutangkis kordinasi mata tangan sangat penting terutama pada saat melakukan pukulan - pukulan. Di dalam pukulan smash kordinasi mata tangan sangat penting peranannya yaitu saat kita melihat bola melambung, tangan memulai ancang - ancang memukul shuttlecock dengan cepat dan tajam ke arah sasaran di lapangan dan ini juga perlunya reaksi dari masing masing individu pemain. Kordinasi merupakan kemampuan untuk mengontrol gerakan tubuh. Seseorang dikatakan mempunyai koordinasi baik bila mampu bergerak dengan mudah dan lancar dalam rangkaian gerakan, iramanya terkontrol dengan baik serta mampu melakukan gerakan yang efisien. Hampir semua gerakan yang dilakukan dalam olahraga dikendalikan dan dikordinasikan secara konstan oleh sistem saraf pusat. Kemampuan gerak motorik yang terkordinasi dengan baik berlangsung secara cepat dan terarah. Dengan kata lain bahwa kecepatan dan ketepatan. Berdasarkan kesimpulan di atas peneliti mengambil kesimpulan bahwa kordinasi mata tangan ialah kemampun untuk mengontrol tubuh saat memukul shuttlecock dengan cepat supaya dapat melakukan long servis dengan tepat dan sempurna.

\section{Hakikat Fleksibilitas Pergelangan Tangan}

Dimana fleksibilitas merupakan bagian dari komponen kebugaran jasmani yang membuat gerakan kita efektif dan efisien, terlihat tidak kaku dan memudahkan kita untuk melakukan aktivitas sehari-hari. Sebagaimana dikemukakan oleh Widiastuti (2011:153) bahwa "Fleksibilitas yang merupakan batas rentang gerak maksimal yang mungkin pada suatu sendi. Berguna untuk efisiensi gerak dalam melakukan aktifitas gerak dan mencegah kemungkinan terjadi cedera. Kemampuan ini diperlukan oleh semua pemain". Menurut Hua dan Aryanto (2007:20) "Karena bulutangkis banyak menggunakan pergelangan tangan".

Ada beberapa keuntungan bagi atlet yang mempunyai kualitas fleksibilitas yang baik, antara lain yaitu: 1) akan memudahkan atlet dalam menampilkan berbagai kemampuan gerak dan keterampilan, 2) menghindarkan diri dari kemungkinan terjadinya pada saat melakukan aktivitas fisik, 3) memungkinkan atlet dapat melakukan gerak yang ekstrem. Berdasarkan uraian di atas dapat disimpulkan bahwa fleksibilitas merupakan kemampuan untuk menggerakan sesuatu agar tidak kelihatan kaku. Jadi, salah satu faktor turut membantu menentukan fleksibilitas pergelangan tangan adalah elastisnya otot atau sendi. Jika fleksibilitas 
pergelangan tangan baik maka dapat berpengaruh pada saat melakukan long servis karena pergelangan tangan akan menghasilkan akhir lecutan dimana shuttllecock akan terjatuh di tempat yang diinginkan.

\section{Hubungan Kekuatan Otot Lengan, Koordinasi Mata Tangan Dan Fleksibilitas Pergelangan Tangan Terhadap Long Servis Bulutangkis \\ Kekuatan otot lengan sangat} mempengaruhi dalam permainan bulutangkis, permainan bulu tangkis sangat memerlukan kekuatan otot lengan dalam melakukan pukulan, dimana setiap pukulan harus menggunakan kekuatan otot lengan sehingga pemain mendapatkan pukulan yang maksimal. Kekuatan merupakan kontraksi yang maksimal untuk menerima beban yang dihasilkan oleh otot atau sekelompok otot. Koordinasi mata tangan sangat diperlukan dalam permainan bulutangkis terutama dalam melakukan servis forehand dimana pada saat bergerak kearah bola sambil mengayun raket, kemudian memukulnya dengan teknik yang benar pemain harus benar-benar harus mempunyai kemampuan koordinasi yang baik. Koordinasi didefinisikan sebagai hubungan yang harmonis dari hubungan saling pengaruh diantara kelompok-kelompok otot selama melakukan kerja. Fleksibilitas merupakan kemampuan untuk menggerakan sesuatu agar tidak kelihatan kaku. Jadi salah satu faktor turut membantu menentukan fleksibilitas pergelangan tangan adalah elastisnya otot atau sendi. Jika fleksibilitas pergelangan tangan baik maka dapat berpengaruh pada saat melakukan servis long forehand karena pergelangan tangan akan menghasilkan akhir lecutan dimana shuttllecock akan terjatuh di tempat yang diinginkan. Berdasarkan uraian di atas, bahwa semakin kuat gerakan tangan maka semakin mampu seseorang mengintegrasikan kordinasi mata tangan dan semakin lentur fleksibiltas pergelangan tangan maka hasil long servis dalam permainan bulutangkis pasti akan lebih bagus pula atau mendapatkan hasil yang maksimal

\section{METODOLOGI PENELITIAN}

Penelitian ini menggunakan metode kuantitatif dengan pendekatan deskriptif. Variabel bebas, kekuatan otot lengan $\left(\mathrm{X}_{1}\right)$, kordinasi mata tangan $\left(\mathrm{X}_{2}\right)$, fleksibilitas pergelangan tangan $\left(\mathrm{X}_{3}\right)$ dan variabel terikat hasil ketepatan long servis (Y). Populasi penelitian mahasiswa Prodi Penjas FKIP UNCEN yang telah memprogramkan mata kuliah Bulutangkis sedangkan sampel diambil dari mahasiswa yang mampu melakukan long servis yang berjumlah 30 Mahasiswa.

Teknik pengumpulan data menggunakan tes antara lain: 1) kekuatan otot lengan menggunakan tes push up, 2) koordinasi mata tangan dengan lemparan tangkap bola tenis, 3) fleksibilitas pergelangan tangan menggunakan alat goniometer, 4) ketepatan long servis dilakukan dengan ketepatan long servis test. Teknik analisis data menggunakan analitis statistik. Untuk menguji hipotesis terlebih dahulu dilakukan uji persyaratan yaitu uji normalitas data dengan 
nilai rasio skewness dan uji homogenitas dengan independent sampel uji $t$ dan dilanjutkan dengan uji $\mathrm{F}$ yang diolah dengan sistem program SPSS versi 21.00.

\section{HASIL DAN PEMBAHASAN}

Uji normalitas dimaksud agar distribusi sampling dari galat taksiran sampel mendekati normalitas populasi. Berikut ini ditampilkan tabel output SPSS uji normalitas dari masingmasing variabel.

\section{Tabel 1.}

Uji Normalitas

\begin{tabular}{|c|c|c|c|}
\hline Variabel & $\begin{array}{l}\text { Kolmogoro } \\
\text { v-Smirnov }\end{array}$ & $\begin{array}{l}\text { Asymp } \\
. \text { sig }\end{array}$ & Keterangan \\
\hline$X_{1}$ & 0,06 & \multirow{3}{*}{0,05} & Normal \\
\hline $\mathrm{X}_{2}$ & 0,49 & & Normal \\
\hline$X_{3}$ & 0,24 & & Normal \\
\hline$Y$ & 0,20 & & Normal \\
\hline
\end{tabular}

Berdasarkan Tabel di atas dapat dilihat bahwa untuk variabel Kekuatan otot lengan sebesar 0,06; untuk Kordinasi Mata-tangan sebesar 0,49; untuk Fleksibilitas Pergelangan tangan sebesar 0,24 dan untuk ketepatan hasil long servis sebesar 0,20. Karena signifikansi untuk seluruh variabel lebih besar dari 0,05 maka dapat disimpulkan bahwa data pada Kekuatan otot lengan, Koordinasi Matatangan, Fleksibilitas Pergelangan tangan, dan ketepatan hasil long servis berdistribusi Normal.

\section{Hubungan Kekuatan Otot Lengan $\left(\mathbf{X}_{1}\right)$ Dengan Ketepatan Hasil Long Servis (Y)}

Koefisien korelasi tersebut harus diuji terlebih dahulu mengenai keberartian (positif) sebelum digunakan untuk mengambil suatu kesimpulan dengan mencari thitung. Adapun hasil Pengujian Hipotesis Koefisien Korelasi antara $\mathrm{X} 1$ dengan $\mathrm{Y}$ tersaji pada tabel 2 berikut ini.

Tabel 2.

Hasil Pengujian Hipotesis Koefisien Korelasi Antara $\mathrm{X}_{1}$ dengan $\mathrm{Y}$

\begin{tabular}{ccccc}
\hline Korelasi & $(\mathbf{r})$ & $\begin{array}{c}\mathbf{T} \\
\text { hitung }\end{array}$ & $\begin{array}{c}\text { ttabel } \\
\boldsymbol{\alpha}=\mathbf{0 , 0 5}\end{array}$ & Kriteria \\
\hline $\mathrm{X}_{1}$ dan Y & 0,779 & 6,581 & 1,701 & $\begin{array}{c}\text { Sangat } \\
\text { tinggi }\end{array}$ \\
\hline
\end{tabular}

Berdasarkan tabel di atas terlihat rhitung $=0,779$ menyatakan tingkat hubungan antara kekuatan otot lengan dengan hasil ketepatan long servis adalah sangat tinggi, dimana nilai $\mathrm{t}_{\text {hitung }}=6,581>\mathrm{t}_{\text {tabel }}=1,701$. Jadi, Ho ditolak yang berarti ada hubungan yang positif antara Power lengan $\left(\mathrm{X}_{1}\right)$ dengan Ketepatan long servis (Y). Besarnya kontribusi (sumbangan) kekuatan otot lengan terhadap Ketepatan long servis bulutangkis dapat ditentukan dengan koefisien determinasi $r^{2} \times 100 \%=0,779^{2} \times 100 \%=60.68 \%$. Artinya, dengan memiliki kekuatan otot lengan yang baik maka ketepatan long servis akan baik pula.

Kekuatan merupakan gaya penggerak, selain itu kekuatan merupakan faktor yang termasuk dalam melakukan ketepatan long servis. Dalam permainan bulutangkis, kekuatan otot lengan yang besar dan kuat akan menghasilkan ketepatan long servis yang baik dan terarah ke daerah lawan yang diinginkan, sehingga dapat menambahkan poin dan membuat lawan meninggalkan strateginya. Karena semakin besar kekuatan otot lengan yang dimiliki seorang pemain bulutangkis maka semakin besar pula tenaga yang dihasilkan pada saat melakukan 
ketepatan servis long forehand sehingga mengasilkan gerakan yang baik dan terarah.

Sebagaimana dikemukakan oleh Oktara (2010:59) "Jenis long servis tinggi digunakan dalam permainan tunggal. Shuttlecock harus dipukul dengan menggunakan tenaga penuh agar Shuttlecock melayang tinggi dan jatuh tegak lurus bagian belakang garis lapangan lawan".

Hubungan kordinasi mata tangan $\left(\mathbf{X}_{2}\right)$ dengan ketepatan hasil Long Servis (Y)

Koefisien korelasi tersebut harus diuji terlebih dahulu mengenai keberartian (positif) sebelum digunakan untuk mengambil suatu kesimpulan dengan mencari thitung. Adapun hasil Pengujian Hipotesis Koefisien Korelasi Antara $\mathrm{X}_{2}$ dengan $\mathrm{Y}$ tersaji pada tabel 3 berikut ini.

\section{Tabel 3.}

Hasil Pengujian Hipotesis Koefisien Korelasi Antara $\mathrm{X}_{2}$ dengan $\mathrm{Y}$

\begin{tabular}{ccccc}
\hline Korelasi & $(\mathbf{r})$ & $\begin{array}{c}\mathbf{T} \\
\text { hitung }\end{array}$ & $\begin{array}{c}\text { ttabel } \\
\boldsymbol{\alpha}=\mathbf{0 , 0 5}\end{array}$ & Kriteria \\
\hline $\mathrm{X}_{2}$ dan $\mathrm{Y}$ & 0,723 & 5,539 & 1,701 & $\begin{array}{c}\text { Sangat } \\
\text { tinggi }\end{array}$ \\
\hline
\end{tabular}

Berdasarkan tabel di atas terlihat rhitung $=0,723$ menyatakan tingkat hubungan antara kekuatan otot lengan dengan hasil ketepatan long servis adalah sangat tinggi, dimana nilai $t_{\text {hitung }}=5,539>t_{\text {tabel }}=1,701$. Jadi, Ho ditolak yang berarti ada hubungan yang positif antara Power lengan $\left(\mathrm{X}_{2}\right)$ dengan Ketepatan long servis (Y). Besarnya kontribusi (sumbangan) kordinasi mata tangan terhadap Ketepatan long servis bulutangkis dapat ditentukan dengan koefisien determinasi $\mathrm{r}^{2} \times 100 \%=$ $0,723^{2} \times 100 \%=52,57 \%$. Artinya dengan memiliki kemampuan koordinasi mata tangan yang baik maka ketepatan long servis akan meningkat.

Dalam Iman Imanudin (2014:64) yaitu teknik dasar ialah semua gerakan yang mendasari permainan, dengan modal tersebut seseorang dapat bermain dengan atau berlatih secara terarah. Selain kemampuan teknik dasar long servis tentunya harus disertai dengan kemampuan Koordinasi mata tangan yang bagus. Koordinasi mata tangan memiliki andil yang cukup besar terhadap penguasaan keterampilan bermain bulutangkis khususnya pada keterampilan long servis. Hal ini mengacu pada penjelasan yang dikemukakan oleh (Bompa 2004:44) yaitu Semakin tinggi tingkat koordinasi seseorang semakin mudah untuk mempelajari teknik dan taktik yang baru maupun yang rumit.

Hubungan fleksibilitas pergelangan tangan $\left(X_{3}\right)$ dengan ketepatan hasil Long Servis (Y) Pengujian Hipotesis Koefisien Korelasi Antara X2 dengan $\mathrm{Y}$ tersaji pada tabel 4 berikut ini.

\section{Tabel 4.}

Hasil Pengujian Hipotesis Koefisien Korelasi Antara $X_{3}$ dengan $Y$

\begin{tabular}{ccccc}
\hline Korelasi & $(\mathbf{r})$ & $\begin{array}{c}\mathbf{T} \\
\text { hitung }\end{array}$ & $\begin{array}{c}\text { ttabel } \\
\boldsymbol{\alpha}=\mathbf{0 , 0 5}\end{array}$ & Kriteria \\
\hline $\mathrm{X}_{3}$ dan $\mathrm{Y}$ & 0,822 & 7,637 & 1,701 & $\begin{array}{c}\text { Sangat } \\
\text { tinggi }\end{array}$ \\
\hline
\end{tabular}

Berdasarkan tabel di atas terlihat rhitung $=0,822$ menyatakan tingkat hubungan antara Fleksibilitas pergelangan tangan dengan hasil ketepatan long servis adalah sangat tinggi, dimana nilai $t_{\text {hitung }}=7,637>t_{\text {tabel }}=1,701$. Jadi, Ho ditolak yang berarti ada hubungan yang positif antara Power lengan $\left(\mathrm{X}_{1}\right)$ dengan Ketepatan long servis (Y). Besarnya 
kontribusi (sumbangan) kekuatan otot lengan terhadap Ketepatan long servis bulutangkis dapat ditentukan dengan koefisien determinasi $r^{2} \times 100 \%=0,822^{2} \times 100 \%=67,56 \%$. Artinya, dengan memiliki fleksibilitas pergelangan tangan yang baik maka ketepatan long servis akan baik pula.

Fleksibilitas adalah salah satu komponen kondisi fisik yang penting untuk ditingkatkan sebagai penunjang dalam long servis. Fleksibilitas identik dengan ruang gerak sendi. Menurut Harsono (2016), Fleksibilitas adalah kemampuan untuk melakukan gerakan dalam ruang gerak sendi. Orang yang memiliki fleksibilitas yang baik akan memiliki ruang gerak sendi yang luas, hal ini akan juga berdampak pada kualitas suatu keterampilan. Fleksibilitas pergelangan tangan yang baik akan memberikan kualitas keterampilan yang baik seperti pada long servis.

Hubungan kekuatan otot Lengan $\left(\mathbf{X}_{1}\right)$, Koordinasi mata tangan $\left(\mathbf{X}_{2}\right)$ dan Fleksibiltas pergelengam tangan $\left(X_{3}\right)$ secara bersama-sama terhadap ketepatan long servis (Y)

Koefisien korelasi tersebut harus diuji terlebih dahulu mengenai keberartian (positif) sebelum digunakan untuk mengambil suatu kesimpulan dengan mencari thitung. Adapun hasil Pengujian Hipotesis Koefisien Korelasi Antara $\mathrm{X}_{1}, \mathrm{X}_{2}, \mathrm{X}_{3}$ dengan $\mathrm{Y}$ tersaji pada tabel 5 berikut ini.

\section{Tabel 5.}

Hasil Pengujian Korelasi Antara $X_{1}, X_{2}, X_{3}$ dengan $Y$

\begin{tabular}{ccccc}
\hline Korelasi & $(\mathbf{r})$ & $\begin{array}{c}\mathbf{F} \\
\text { hitung }\end{array}$ & $\begin{array}{c}\mathbf{f}_{\text {tabel }} \\
\boldsymbol{\alpha}=\mathbf{0 , 0 5}\end{array}$ & Kriteria \\
\hline
\end{tabular}

$\mathrm{X}_{123}$ dan $\mathrm{Y} \quad 0,942 \quad 68,110 \quad 2,98 \quad \begin{gathered}\text { Sangat } \\ \text { tinggi }\end{gathered}$

Berdasarkan tabel 5 terlihat rhitung $=$ 0.942 menyatakan tingkat hubungan antara kekuatan otot lengan $\left(\mathrm{X}_{1}\right)$ dan koordinasi mata-tangan $\left(\mathrm{X}_{2}\right)$ fleksibilitas pergelangan tangan $\left(\mathrm{X}_{2}\right)$, terhadap ketepatan long servis bulutangkis (Y) adalah sangat tinggi, dimana nilai Fhitung $=68,110>$ Ftabel $=2,98$ pada taraf positifsi $\alpha$ 0,05. Jadi, Ho ditolak yang berarti ada hubungan kekuatan otot lengan $\left(X_{1}\right)$ dan koordinasi mata-tangan $\left(X_{2}\right)$ fleksibilitas pergelangan tangan $\left(\mathrm{X}_{3}\right)$ terhadap ketepatan long servis bulutangkis (Y). Besarnya kontribusi (sumbangan) kekuatan otot lengan, kordinasi mata tangan dan fleksibilitas pergelangan tangan, terhadap ketepatan long servis bulutangkis dapat ditentukan dengan koefisien determinasi $\mathrm{r}^{2} \mathrm{x}$ $100 \%=0,942^{2} \times 100 \%=88,73 \%$ artinya, dengan memiliki kekuatan otot lengan, koordinasi mata-kaki dan fleksibilitas pergelangan tangan yang baik maka seorang pemain akan mampu melakukan ketepatan long servis bulutangkis dengan sempurna.

\section{KESIMPULAN DAN SARAN}

1. Ada hubungan yang berarti antara kekuatan otot lengan terhadap ketepatan long servis dalam permainan bulutangkis pada mahasiswa Prodi Penjas FKIP UNCEN.

2. Ada hubungan yang berarti antara kordinasi mata tangan terhadap ketepatan long servis dalam permainan bulutangkis pada mahasiswa Prodi Penjas FKIP UNCEN 
3. Ada hubungan yang berarti antara fleksibilitas terhadap ketepatan long servis dalam permainan bulutangkis pada mahasiswa Prodi Penjas FKIP UNCEN

4. Ada hubungan yang berarti antara kekuatan otot lengan, kordinasi mata tangan dan Fleksibilitas pergelangan tangan terhadap ketepatan servis panjang dalam permainan bulutangkis pada mahasiswa Prodi Penjas FKIP UNCEN

\section{DAFTAR PUSTAKA}

Agryant, K. (2017). Hubungan Antara Kekuatan Otot Perut dan Koordinasi Mata Tangan Terhadap Ketepatan Smash Di UKM Bulutangkis Universitas Muhammadiyah Sukabumi Tahun 2017. Sukabumi: Tidak Diterbitkan.

Aksan, Hermawan. (2013). Mahir Bulu Tangkis. Bandung: Nuansa Cendekia.

Antoni. (2017). Journal of Kependidikan "Kontribusi Daya Ledak Otot Tungkai dan Kelentukan Pergelangan Tangan Terhadap Ketepatan Smash Bulutangkis". Universitas PGRI Palembang

Arikunto, S. (2013). Prosedur Penelitian: Suatu Pendekatan Praktik. Jakarta: Rineka Cipta.

Bompa. (2004). Klasifikasi Latihan. Pustaka Indonesia. Jakarta.

Harsono. (2016). Latihan kondisi fisik (untuk atlet dan kesehatan). Bandung: FPOKUPI Bandung.

Hua, H. dan Aryanto, S. (2007). Bulu Tangkis. Klaten: PT Macanan Jaya Cemerlang.
Ismaryati. (2011). Tes Dan Pengukuran

Olahraga. Surakarta: Universitas Sebelas Maret.

Kusnaedi, dkk. (2016). Jurnal Sains Keolahragaan dan Kesehatan. Pengaruh Metode Latihan Dan Koordinasi Terhadap Keterampilan Smes Bulutangkis.

Kunta, Purnama Sapta, (2010). Kepelatihan Bulutangkis Modern. Surakarta: Yuma Pressindo.

Oktara (2010), Aktivitas Ketangkasan dan Beladiri. Depok: Binamuda.

Satriya., S. Dikdik Z \& Imanudin, Iman. (2014). Bahan Ajar Teori Latihan Olahraga. Bandung: PKO FPOK UPI

Sugiyono (2015). Metode Penelitian Kombinasi (Mix Methods). Bandung: Alfabeta.

Widiastuti. (2015). Tes dan Pengukuran Olahraga. Jakarta: Rajawali Press. 